\title{
Cellular Division and Reproduction of Bacteriophage in Synchronized Cultures of Escherichia coli
}

\author{
BY J. STARKA \\ Department of Microbiology, Charles University, Viničná 5, Prague 2, \\ Czechoslovakia
}

(Received 3 October 1961)

SUMMARY

\begin{abstract}
Bacteriophage T2r inhibits the division of the host cell Escherichia coli B, immediately after adsorption. Synchronized cells, when infected by phage at the moment of cell division, cannot carry this process to completion. The same effect is exhibited by phage inactivated by ultraviolet light. In contrast, bacteriophage $\phi x-174$ allows infected cells to divide before lysis. Determination of the rate of synthesis and final yield of virus showed that synchronized cells from the middle period between two divisions produced the highest burst sizes, whereas the lowest burst sizes were observed in dividing cells.
\end{abstract}

\section{INTRODUCTION}

It is generally accepted that infection of bacterial cells by bacteriophage may inhibit growth and further cell division. However, methods such as microscopic observation or turbidity measurements of randomly dividing bacteria cannot decide whether a cell dividing at the moment of infection can complete this process or whether it is completely inhibited immediately after the phage is adsorbed. The inhibitory effect of virulent bacteriophage on bacterial division was studied in the light microscope by Luria \& Delbrück (1942) but these authors concluded that their method did not give any definite answer to this question. On the other hand, it has been concluded that certain temperate phages allow the infected cell to divide once or twice before lysis (Lwoff, Siminovitch \& Kjeldgaard, 1950).

Cell division, although closely dependent upon growth, is believed to involve some more or less specific mechanisms (Swann, 1957). It is, therefore, not selfevident that the growth-inhibiting action of virulent bacteriophage must necessarily be accompanied by simultaneous inhibition of cell division. Synchronization of bacterial division facilitates the study of this interesting problem. In addition it enables one to relate the final yield of virus to the stage in the cell-division cycle at which the cells are infected. The effect of bacteriophage on synchronously dividing Escherichia coli was reported in a previous communication (Stárka \& Koza, 1958). When cells were infected immediately before an expected division, a slight increase in the intensity of scattered light was observed, indicating that probably some cells divided before lysis.

Virus synthesis in bacteria dividing synchronously was first studied by Barner \& Cohen (1956) using Escherichia coli $15 \mathrm{~T}^{-}$and bacteriophage $\mathbf{T} 2 r^{+}$. The results indicated that bacteriophage adsorption and yield were essentially independent of 
the stage of host development at the time of infection, at least under the special conditions of their experiments. On the other hand, Yanagita, Maruyama \& Takebe (1958), using a filtration method of synchronization, observed significant differences in the amount of phage adsorbed by synchronized cells depending on the increase of cell surface during the cell-division cycle. The burst sizes in one-step growth experiments with bacteria infected at different phases of synchronized growth also varied significantly and the highest values were obtained with cells midway between two divisions. In agreement with the conclusions of Yanagita et al. (1958), the importance of the actual state of the growing cell at the time of infection by phage for the yield of virus was also described in our preceding report (Stárka \& Koza, 1958) where cold shock treatment was used as a method of synchronization. The apparent contradiction between the results of Barner \& Cohen (1956) and these later observations might be explained by the different methods of synchronization, i.e. by withdrawal and addition of an essential metabolite in the first case, and by filtration or cold shock in the second.

The present study was begun in an attempt to throw more light on two problems, namely whether phage inhibits the division process of already dividing bacteria; and how the rate of synthesis and final yield of virus varies in synchronized cultures.

\section{METHODS}

Organisms and growth methods. A streptomycin-resistant strain of Escherichia coli $\mathbf{B}$ was used and the division cycle was synchronized by a single temperature shift as described previously (Stárka \& Koza, 1959). The growth medium was Bacto Tryptose Broth (Difco) 0.5\% (w/v) and 0.085 $\mathrm{M}-\mathrm{NaCl}$, pH 7.

Single-step growth curves and single cell bursts were determined at $30^{\circ}$ with bacteriophage T2r using the techniques described by Adams (1950, 1959) except that all dilutions were made in tryptose medium instead of in broth, and the temperature for phage growth was maintained at $30^{\circ}$. The burst size in nonsynchronized cells at $30^{\circ}$ was found to be 90 , with a latent period of $40-45 \mathrm{~min}$. At $37^{\circ}$ the burst size was 100 , latent period $26 \mathrm{~min}$. The multiplicity of infection in all burst-size determinations was between 0.08 and $0 \cdot 1$.

Phage T $2 r$ inactivated by ultraviolet light (u.v.) was prepared according to Luria \& Delbrück (1942). After irradiation, the phage suspension contained $2 \times 10^{4}$ plaque-forming particles and $3 \times 10^{9}$ inactivated phages per $\mathrm{ml}$.

In experiments with phage $\phi \times 174$, Escherichia coli $\mathrm{C}$ was used as bacterial host. The growth medium contained tryptose $0.5 \%(\mathrm{w} / \mathrm{v}), 0.085 \mathrm{M}-\mathrm{NaCl}$ and $2 \cdot 5 \times 10^{-3} \mathrm{M}-\mathrm{CaCl}_{2}$.

Optical method of bacterial count. Bacterial counts were determined using a Pulfrich nephelometer. In this instrument the incident light is scattered by suspended bacteria and collected by a converging lens at an angle of $45^{\circ}$. The intensity of the light scattered by the sample is compared with the intensity of light passing through an opal glass diffusing plate and can be adjusted by means of a diaphragm. A scale on the diaphragm ranges from zero (slit closed) to 100 (slit fully opened). In the range 0-70 of the nephelometer readings (N.R.) the number of bacteria per $\mathrm{ml}$. determined by plating and by counting in a counting chamber is directly proportional to the intensity of the scattered light. Using selected Pyrex tubes (internal 
diameter $15 \mathrm{~mm}$.) as cuvettes, 1 division (N.R.) represents $5 \times 10^{5}$ bacteria $/ \mathrm{ml}$. Under the experimental conditions described here the intensity of the scattered light is considered to depend only on the particle count and not to be related to increase in cell mass. Moreover, change in volume of the particles within certain limits (e.g. dividing bacteria) has little effect on the relation of the particle count to the nephelometer reading (Koch, 1961).

\section{RESULTS}

Inhibition of cellular division by phage. The influence of bacteriophage infection on cellular division was followed directly in synchronized cultures of bacteria. Phage was added to $10 \mathrm{ml}$. samples of cultures in different phases of the division cycle at an input ratio of phage:bacteria of $20: 1$. These samples were shaken separately in

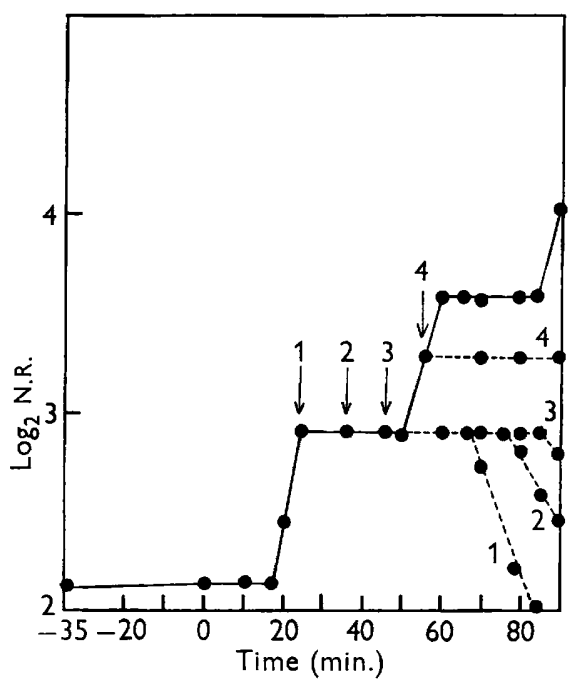

Fig. 1. The effect of bacteriophage $T 2 r$ on cell division in a synchronized culture of Escherichia coli $B$. Phage was added to non-dividing cells $(1,2,3)$ and to already dividing cells (4). Dashed curves show the nephelometer readings (N.R.) of samples after infection. The solid line represents the light scattering of non-infected control. Phage/ bacteria ratio $=20: 1$; temperature $30^{\circ}$.

tubes. In non-infected controls the growth rate and division time were identical with the parameters of the stock culture. Five min. after addition of phage, essentially all bacteria were infected.

Figure 1 shows a typical growth curve of synchronized bacteria and the effect of added phage on bacterial division. The time of one division cycle was approx. $35 \mathrm{~min}$. In repeated experiments it varied between 30 and $35 \mathrm{~min}$. This is in good agreement with the generation time of $34 \mathrm{~min}$. for a non-synchronized control. It appears that the growth rate of synchronized bacteria is not altered by cold treatment. If the time of completed division was considered as 0 , then infection of bacteria at 0, 10 and 20 min. (Fig. 1, points 1, 2 and 3) resulted in lysis after approx. $40 \mathrm{~min}$. without even a transient increase in the intensity of scattered light. Thus the division of bacteria was completely arrested by the infecting virus even if it was 
added only $5 \mathrm{~min}$. before the next expected division. A remarkable property of phage in connexion with dividing bacteria is illustrated by the fact that addition of phage to a culture of already dividing cells (Fig. 1, point 4) stopped further increase in the intensity of scattered light. This shows that the division process was immediately inhibited by adsorbed phage. When the input of phage was 100:1 or more, a transient increase in intensity of scattered light was previously observed when cells were infected 5 min. before expected division (Stárka \& Koza, 1958). Phase-contrast microscopy showed that loss of rigidity of the cell wall was accompanied by swelling of paired cells and by their separation. This, and the transient increase in light scattering, were probably caused by the action of the lytic enzyme of the phage tail. Fifteen minutes after addition of phage (input 100:1) complete lysis was observed in all samples ('lysis from without'-Delbrück, 1940).

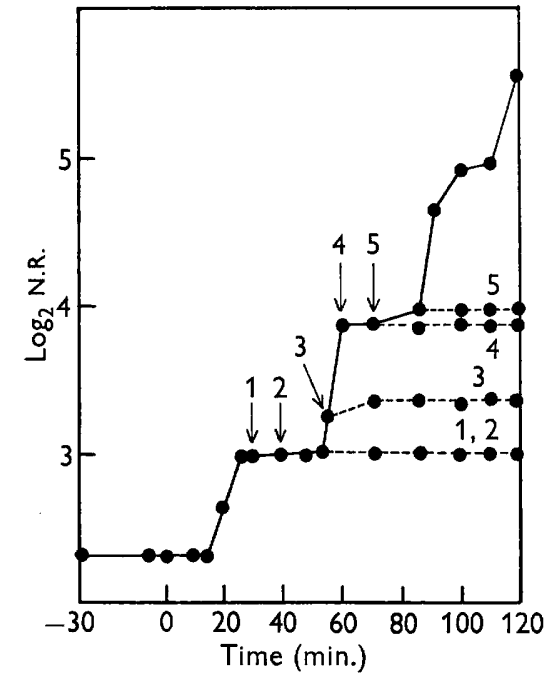

-Fig. 2

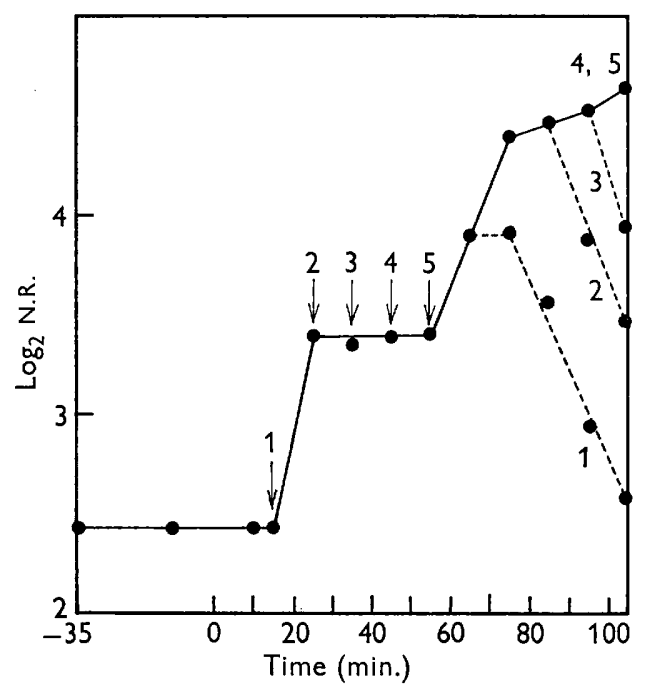

Fig. 3

Fig. 2. The effect of u.v.-inactivated phage T2 $r$ on cell division in a synchronized culture of Escherichia coli B. Inactivated phage/bacteria ratio $=4: 1$. (Compare with Fig. 1.)

Fig. 3. The effect of bacteriophage $\phi \times-174$ on a synchronized culture of Escherichia coli C. Phage/bacteria ratio $=5: 1$. (Compare with Fig. 1.)

Similar experiments were performed with u.v.-irradiated phage containing a negligible fraction of plaque-forming survivors $\left(1: 1.5 \times 10^{5}\right)$. Inactivated particles of T $2 r$ phage were added at intervals to the samples of synchronized bacteria. Input ratio of inactivated phage: bacteria was $4: 1$. The results of these experiments show that the irradiated phage did not differ from intact virus in its immediate action on dividing cells. In Fig. 2, point 3 represents the effect of inactivated phage on already dividing cells. The slight increase in nephelometer reading indicates division of a small fraction of bacteria during adsorption. When the input ratio was increased to 20:1, no such increase was recorded.

Závada (personal communication) demonstrated that Escherichia coli $\mathrm{C}$ infected by bacteriophage $\phi \mathrm{x}-174$ was still able to synthesize $\beta$-galactosidase when induced 
during the latent period. Turbidity measurements indicated that the host cells continued to grow until the first signs of lysis. In our studies, Escherichia coli $\mathbf{C}$ was synchronized as described above. Bacteriophage $\phi x-174$ was added to the samples of synchronized cells in a phage/bacteria ratio of 5:1. Figure 3 shows that the division of infected cells was not affected by phage during the whole of the latent period. Considering that at $30^{\circ}$ this lasts approx. $55 \mathrm{~min}$. it is possible that some cells may divide twice after infection. Thus, bacteriophage $\phi x-174$ behaves similarly to temperate phages (Lwoff, Siminovitch \& Kjeldgaard, 1950).

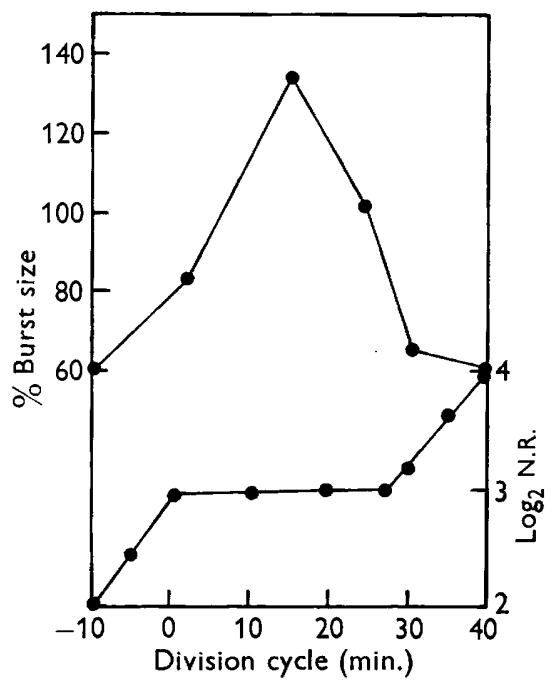

Fig. 4. Burst size of synchronized cells of Escherichia coli $\mathbf{B}$. Phage yields from bacteria withdrawn at different phases of the division cycle (lower curve) were determined by single-cell method and by single-step growth experiments and plotted (upper curve) as percentage of burst size in a randomly dividing culture.

\section{Phage yields of synchronized bacteria}

Figure 4 shows the burst sizes obtained by means of single-cell determinations of phage yields from synchronized bacteria. The average burst size from non-synchronized cells was 92. Synchronized cells which had just completed division ( 0 min.) gave a value of 62 and cells from between two subsequent divisions (15 min.) gave an average burst size of $\mathbf{1 4 5}$. The differences were statistically significant. The distribution of burst sizes of individual bacteria from samples of synchronized cells is shown in Fig. 5. It appears that the burst size distribution of randomly dividing bacteria is wider than that of synchronized cells.

These findings were checked with burst size determinations obtained by means of single-step growth experiments. Samples of synchronized host cells were withdrawn at different phases of the division cycle and infected by phage. The latent period preceding liberation of vegetative phage was determined using bacteria from various points of the division cycle which was found to vary between 40 and $45 \mathrm{~min}$. It appears that the rate of synthesis of new phage particles is not related to the division cycle of the host. On the other hand, the burst size depended significantly 
on the time at which the bacteria were infected. Assuming that variations of adsorption rate during division cycle (Yanagita et al. 1958) did not play an important role in these experiments, the input ratio of phage:bacteria was always the same. Burst size determined by this method varied in the same range as in the single-cell burst determinations. The average burst size from randomly dividing cells was 87. Synchronized cells in 0 min. gave a burst of 51 and cells from the middle period between two divisions ( 15 min.) gave a value of 139 (see Fig. 4).

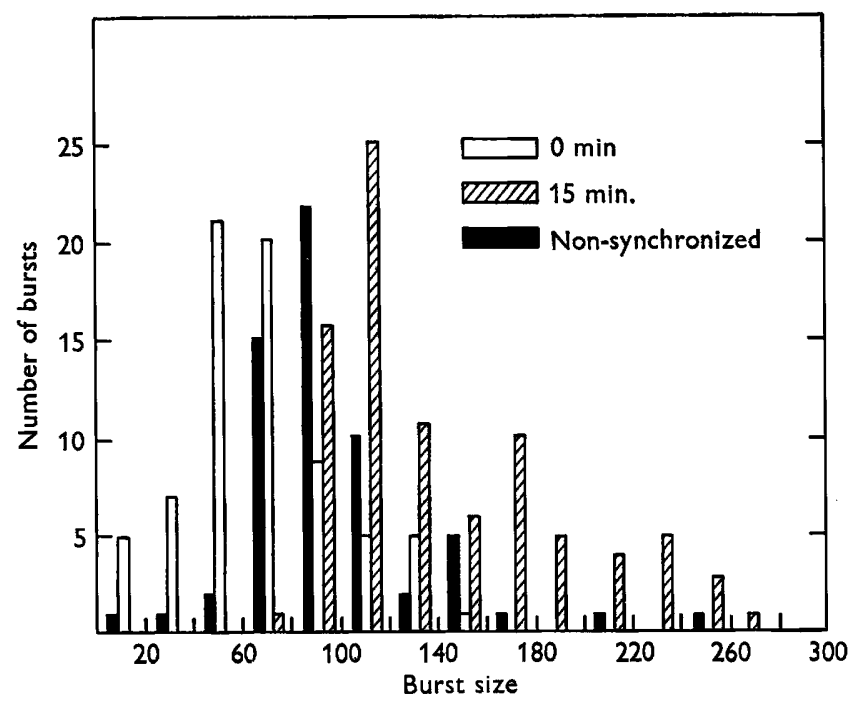

Fig. 5. Distribution of burst sizes from synchronized and non-synchronized cultures of Escherichia coli B infected with bacteriophage T2r. Data labelled 0 min. are from cultures in which cells had just completed division; data labelled $15 \mathrm{~min}$. from culture in which cells were mid-way between divisions. Data are derived from 5 independent experiments with approx. $20 \%$ samples showing bursts. (See Fig. 4.)

It appears, therefore, that during cell division the extent to which the cell can reproduce the virus is lowered and reaches a maximum between divisions. In nonsynchronized cultures growing exponentially the burst size represents a composite of that from dividing and non-dividing cells.

\section{DISCUSSION}

The killing effect of $\mathbf{T} \mathbf{2}$ bacteriophages on bacterial cells is complex and involves the inhibition of the division of infected bacteria. The use of a nephelometric technique allows precise determinations to be made of the actual number of bacterial cells irrespective of size, and has demonstrated that infection of Escherichia coli by phage T $2 r$ prevents division even of those cells which were on the point of dividing. It may be that the lytic enzyme present in the phage tail causes some structural alterations in the cell wall the integrity of which is essential for division. The almost instantaneous inhibition of cellular division by phage could also be explained by an abrupt inhibition of synthesis of bacterial ribonucleic acid, which is well known to participate in cellular division (Swann, 1957). It has been established that the 
synthesis of nucleic acids and proteins by the cell is drastically altered shortly after infection by phage (Cohen, 1947; Monod \& Wollman, 1947; Brenner, Jacob \& Meselson, 1961). T2 'ghosts' and phages irradiated by u.v. or X-rays and unable to multiply have the same killing properties as have intact phage (Garen \& Kozloff, 1959) and one of the important properties of phage 'ghosts' is that they inhibit the synthesis of host ribonucleic acid (Herriot \& Barlow, 1957). It cannot, however, be excluded that inhibition of cell division involves both the phage lytic enzyme and interference with nucleic acid metabolism. It is, perhaps, relevant that temperate phages do not interfere as greatly with the metabolism of the host as does the virulent phage T2 (Jacob \& Wollman, 1959). This may be why they do not affect the division mechanism of the host cell. Bacteriophage $\phi x-174$ resembles the temperate phages in allowing the host cell to divide during the whole latent period.

In his paper Delbrück (1940) showed that the number of phage particles released from infected host cells depended on the physiological state of the host bacterium. With actively dividing bacteria the burst size was 170 and with resting cells it was only 20. The latent periods were 17 and $\mathbf{3 0}$ min., respectively. Another observation indicating the importance of the physiological state of the host cell was made by the same author (Delbrück, 1945). In experiments employing the singlecell technique, burst sizes varied from less than 20 to over 1000. This large fluctuation was explained by some feature in the mechanism of intracellular virus growth. In our experiments the variation of burst sizes was in the range from 10 to 280 only, but there was a significant difference in fluctuation range between nondividing and dividing cells from synchronized cultures. It seems that the large fluctuation of burst sizes of randomly dividing bacteria could be explained at least in part by the variation in burst size depending on the division cycle of the host.

The observations of Yanagita et al. (1958) on burst size variations during the division cycle are confirmed and extended by our results despite the use of a completely different method of synchronization. But our findings differ from those of Barner \& Cohen (1956) who used a third method-that of 'unbalanced growth' resulting from temporary withdrawal of an essential metabolite. Considering the fact that the balanced growth is affected only slightly by cold shock and to an even lesser extent by filtration, it may be assumed that the final yield of virus particles from an infected bacterium growing under normal conditions is influenced both by its physiological state and its position in the cell division cycle.

Why the cell synthesizes fewer bacteriophages when infected at the time of division as yet remains unknown, since our understanding of the dual problem of cellular division and virus multiplication remains incomplete.

\section{REFERENCES}

Adams, M. H. (1950). Methods of study of bacterial viruses. Meth. med. Res. $2,1$.

Adams, M. H. (1959). Bacteriophages. New York and London: Interscience.

Barner, H. D. \& Cohen, S. S. (1956). Synchronization of division of a thymineless mutant of Escherichia coli. J. Bact. 72, 115.

Brenner, S., Jacob, F. \& Meselson, M. (1961). An unstable intermediate carrying information from genes to ribosomes for protein synthesis. Nature, Lond. 190, 576.

CoHen, S. S. (1947). The synthesis of bacterial viruses in infected cells. Cold Spr. Harb. Symp. quant. Biol. 12, 35. 
Delbrück, M. (1940). The growth of bacteriophage and lysis of the host. J. gen. Physiol. $23,643$.

DeLbRÜCK, M. (1945). The burst size distribution in the growth of bacterial viruses. J. Bact. 50, 131.

Garen, A. \& Kozloff, L. M. (1959). The initiation of bacteriophage infection. In The Viruses, p. 203. Ed. F. M. Burnet and W. M. Stanley. New York and London: Academic Press.

Herriott, R. M. \& Barlow, J. L. (1957). The protein coats or 'ghosts' of coliphage ' $T_{2}$. Preparation, assay and some chemical properties. J. gen. Physiol. 40, 809.

JaCOB, F. \& Wollman, E. (1959). In Adams, M. H., Bacteriophages. New York and London: Interseience.

KocH, A. L. (1961). Some calculations on the turbidity of mitochondria and bacteria. Biochim. biophys. Acta, 51, 429.

LuRIA, S. E. \& DeLBRücK, M. (1942). Interference between inactivated bacterial virus and active virus of the same strain and of a different strain. Arch. Biochem. 1, 207.

Lwoff, A., Siminovitch, L. \& KJeldgaArd, N. (1950). Induction de production de phage dans une bactérie lysogène. Ann. Inst. Pasteur, 79, 815.

Monod, J. \& Wollman, E. (1947). L'inhibition de la croissance et de l'adaptation enzymatique chez les bactéries infectées par le bactériophage. Ann. Inst. Pasteur, 73, 937.

StánKa, J. \& KozA, J. (1958). The effect of bacteriophage on synchronized culture of Escherichia coli. VIIth Int. Congress Microbiol., Stockholm, p. 43.

StÁRKA, J. \& KoZA, J. (1959). Nephelometric determination of cell count in synchronously dividing cultures of bacteria. Biochim. biophys. Acta, 32, 261.

Swand, M. M. (1957). The control of cell division: a review. I. General mechanisms. Cancer Res. 17, 727.

Yanagita, T., MaruYama, J. \& TAKeBE, B. (1958). Cellular response to deleterious agents during the course of synchronous growth of Escherichia coli. J. Bact. 75, 523. 